\title{
Tradição acadêmica no Brasil e formação do homo academicus: o caso da Academia Brasileira de Letras
}

MAURÍCIO SILVA*

Resumo: $O$ presente artigo analisa o contexto cultural do pré-modernismo brasileiro, destacando o processo de canonização do autor pela historiografia literária e revela outros aspectos estéticos e literários da Literatura Brasileira. Além disso, este artigo analisa as possíveis relações entre autores pré-modernistas e a Academia Brasileira de Letras, durante a passagem do século XIX para o XX.

Abstract: The present article analyses the cultural context of Brazilian premodernism, and points out the process of canonization by the literary historiography, and it reveals some aesthetic and literary aspects of Brazilian Literature. Furthermore, the present article analyzes the relationship between the premodernist writers and the Brazilian Academy of Letters, detaching the institutionalizations issues on the turn-of-the-century.

Palavras-chave: Pré-Modernismo. Literatura Brasileira. Historiografia literária.

Key words: Premodernism. Brazilian Literature. Literary historiography.

Um dos fenômenos mais curiosos e instigantes da Historiografia Literária brasileira é o aparecimento, no final do século XIX, de um movimento academicista que se forma no Rio de Janeiro, a partir do qual buscam-se equacionar, num mesmo conjunto de atitudes sociais e representações literárias, uma ética e uma estética rigidamente reguladas. Não se trata, evidentemente, do mesmo academicismo presente no Brasil desde o século XVII e que ganha particular expressão social no século seguinte, o qual já fora estudado por nossa historiografia de forma relativamente ampla.

* Professor no Centro Universitário Nove de Julho (UNINOVE); Doutor e Pós-Doutor pela USP. E-mal: maurisil@gmail.com

Estudos Ibero-Americanos, PUCRS, v. XXXIV, n. 2, p. 188-203, dezembro 2008 
Sem surgir como uma ação continuada do academicismo setecentista, esse novo movimento acadêmico revela-se uma tendência até certo ponto autônoma, nascida antes de um projeto deliberado de preservação da língua nacional, consolidação da produção literária brasileira e institucionalização de um conjunto de princípios estéticos, regidos - no plano da sociabilidade, isto é, da vida literária, mais do que da literatura - por uma ética espontaneamente incorporada por autores e intelectuais do período.

Não se pode negar, contudo, que algumas de suas características mais flagrantes mantêm uma clara relação - ainda que mais simbólica que histórica - com o movimento academicista de dois séculos atrás, sobretudo naquilo que se refere ao ideário encomiástico que movia seus pares, às estratégias de preservação de seus membros, ao retoricismo estilístico e lingüístico, ao sentido gregário e ao corporativismo do grupo e, finalmente, ao profundo sentimento de aristocracia cultural que presidia a instituição academicista. Todas estas práticas, evidentemente, traduziam-se em atitudes cujo alcance ultrapassava os limites estreitos da atividade literária, ganhando, inclusive, um sentido mais explicitamente político, na medida em que - ao lado do projeto de constituição de um sistema literário amplo, que envolvia escritores, leitores, instituições legitimadoras etc. - verificavam-se, tanto antes quanto depois, esforços no sentido de consolidação de uma literatura efetivamente nacional e da constituição de uma sociabilidade literária definida a partir de padrões de comportamento prédeterminados. As principais diferenças, contudo, ficam por conta das várias idiossincrasias que o academicismo do século XVIII possuíam, configurando-se, nas palavras de um estudioso do assunto, no "movimento cultural mais complexo e legítimo que tivemos em toda a era colonial" e caracterizando-se pelo reforço "do sentimento nativista", pelo desenvolvimento de "uma atividade crítica orientada e valorizadora sobretudo dos estudos históricos e científicos" e pela intensificação de "estudos dos aspectos fundamentais de nossa vida e de nossa formação", tudo regido por um flagrante "esforço de unificação" da colônia (Castello, 1968, p. 311; Castello, 1969; Castello, 1975).

Não eram exatamente estes os propósitos declarados do academicismo finissecular, que estava muito mais ligado a um projeto de valorização e preservação do profissional da escrita do que a veleidades nativistas e ideários de afirmação de uma identidade própria. Contudo, se há diferenças de fundo, há ainda 
outras semelhanças de superfície, sobretudo no que concerne a alguns fenômenos meramente episódicos e pontuais, como o fato de as academias de ambos os séculos possuírem representantes efetivos e correspondentes, sendo aqueles em número de quarenta, com igualdade de direito em relação ao voto, obrigatoriedade de se fazer o elogio do antecessor no momento da posse etc.; ou como o ideário encomiástico que preside a atuação de ambas as academias, presente por "determinação estatutária" (Lima, 1980, p. 66) no academicismo do século XVIII e servindo como sustentação ideológica e institucional para o academicismo durante a passagem do século XIX ao XX: índice mais importante daquela estratégia de preservação própria da instituição acadêmica, o ideário enco miástico inclui-se, aliás, em uma substancial tendência ao corporativismo, buscando, por meio do elogio mútuo e até do autoelogio, uma afirmação mais garantida na cultura brasileira. Tal ideário emerge, assim, como resquício de práticas acadêmicas próprias do século XVIII, estas também afeitas a estratégias de conservação/valorização de seus membros por meio de práticas laudatórias. Nas palavras de José Aderaldo Castello, as academias do século XVIII caracterizavam-se pelo "panegírico e elogio de qualquer natureza", com uma visível "tendência para o encômio e para a bajulação" (Castello, 1975, p. 85). Tal perspectiva é, igualmente, ressaltada por Afrânio Coutinho - ao tratar das academias do setecentismo -, para quem, "à sombra das academias literárias, pratica-se uma literatura anêmica e sensaborona, literatura empolada, de louvação e encômios, numa linguagem farfalhante, carregada de exagerado metaforismo e conceitos arrevesados" (Coutinho, 1988, p. 125).

Evidentemente, semelhantes afirmações necessitam ser relativizadas, na medida em que a sociedade portuguesa do século XVIII era definida, segundo o Direito Canônico então vigente, como "corpo místico" de estamentos e ordens subordinados ao regente, fazendo com que o encômio e a bajulação tivessem também uma função de reforço do corpo político do Estado, reiterando o pacto de sujeição que vigorava entre súditos e regente. ${ }^{1}$ Não obstante, as afirmações acima transcritas podem ser quase literalmente adotadas para explicar o que se passava, por exemplo, já em fins do século

1 Agradeço a João Adolfo Hansen por essa informação, que ponderou, com muita propriedade, o sentido político subjacente às práticas laudatórias promovidas pelos acadêmicos setecentistas. 
XIX, entre os componentes da Academia Brasileira de Letras, que, com algumas raras exceções, adotavam integralmente a estratégia do elogio explícito, numa flagrante tendência ao corporativismo.

\section{O ideário encomiástico e a Academia Brasileira de Letras}

Na prática, o panegírico acadêmico tanto poderia ser verificado nas sessões internas da Academia, concentrado em discursos de recepção de novos agregados e afins, quanto fora do ambiente acadêmico, disseminado em livros e periódicos mundanos em geral. É assim que, ao lado de obras assumidamente encomiásticas, como o tardio Nós, as Abelhas (1936), de Martins Fontes, e de revistas que destinavam seções exclusivas para a troca mútua de elogios, como A Semana (1885-1895), de Valentim Magalhães, era possível se deparar com afirmações declaradamente encomiásticas, como a alocução que Coelho Neto pronunciou em 1926, ao assumir a presidência da Academia Brasileira de Letras, afirmando, num exemplo comum de falsa modéstia, que

a roda que formamos em volta de um ideal tem quarenta raios, todos iguais e todos girando com a mesma diligência no movimento de marcha. Chegou a minha vez de culminar. Isto, porém, não significa que eu me tenha destacado de vós em preeminência - tudo é uma questão de volteio (Coelho Neto, 1928, p. 105).

Asserções como essa eram bastante comuns nos discursos de recepção de novos acadêmicos, quando o elogio se tornava muito mais incisivo e pessoal. Nem sempre, contudo, o elogiado era propriamente um dos agregados; às vezes, a apologia direcionavase para a instituição acadêmica como um todo, atingindo por extensão seus associados. É o que se pode perceber nas palavras do acadêmico Augusto de Lima que, em crônica escrita em 1919 para o jornal $A$ Noite, destacava a importância da Academia para a pátria brasileira:

a Academia não é uma simples associação particular, mas uma fundação nacional, zelada com carinho pelos poderes publicos, que nella têm um collaborador espontaneo para a realização da principal missão do Estado - educar e instruir(Lima, 1923, p. 127);

ou, ainda, nas palavras de outro acadêmico, durante a inauguração dos bustos de acadêmicos eméritos, em que Sousa Bandeira adota a mesma perspectiva nacionalista de seu confrade e, numa sintomática alusão à Academia como sendo "a nossa corporação", afirma: 
já passou para a Academia a época das lutas iniciais. Agora tem firmada a sua individualidade. É indiscutível a sua influência. $O$ ardor com que as mais notáveis personalidades procuram fazer parte dela, a violencia mesma dos ataques que lhe são dirigidos, provam suficientemente ser ela uma força nacional (Bandeira, 1917, p. 189).

Entre a fundação nacional do primeiro e a força nacional do segundo, a diferença é apenas formal, posto que o sentido seja o mesmo, já que ambos compactuam do espírito apologético que prevalece na época em torno da Academia, um espírito, aliás, largamente difundido entre quase todos os membros da agremiação.

Outra maneira de propagar esse sentido de autopreservação acadêmica era atuar em campo inverso do mútuo louvor, uma tática que, embora por caminhos transversos, participava do mesmo ideário encomiástico a que aludimos há pouco: ao invés de elogiar os amigos, partia-se para o ataque aos inimigos, enfatizando a atmosfera corporativista que prevalecia no ambiente acadêmico. Os ataques tinham como objetivo o combate aos chamados novos, fossem eles os simbolistas, que - a partir de uma estética antiparnasiana e, por extensão, anti-acadêmica - propunham uma nova relação arte/sociedade, inclusive no que diz respeito à pragmática literária; fossem eles os modernistas, igualmente antiacadêmicos, mas agora com propostas diferenciadas no campo artístico, a partir de um ideário vanguardista de renovação estética. Os simbolistas foram, sem dúvida, os mais atacados: chamados pejorativamente de novos, eram execrados pela quase absoluta maioria dos acadêmicos, que os viam menos como uma ameaça a uma posição social já há muito consolidada do que como um empecilho aos seus ideais de homogeneização estética. Via de regra, eram tomados como decadentes, mais preocupados com um excessivo culto de uma personalidade desviante do que com o profissionalismo nas letras; mais voltados para uma "mística" literária que abrigava todos os exageros simbólicos do que com o culto à perfeição formal; mais ocupados com a imposição de um novo estilo de vida entre os jovens literatos do que com a sujeição "natural" desses mesmos jovens aos princípios éticos que regiam a sociabilidade acadêmica. Assim, os simbolistas não só passaram a ser alijados do convívio social dos acadêmicos, mas também amargaram um quase que completo ostracismo em termos de publicação, divulgação e recepção de suas obras. Parece haver, desse modo, certo consenso na Historiografia Literária nacional de 
que a derrota dos simbolistas diante dos parnasianos/acadêmicos deveu-se antes à própria incapacidade daqueles de impor seus ideais estéticos, já que, como afirmou Machado Neto, "a inapetência social dos simbolistas os incapacitou para a vitória sobre o parnasianismo-naturalismo dominante, na pugna pela vigência intelectual" (Machado Neto, 1973, p. 208; Moises, 1984; Murici, 1952).

Em relação aos modernistas, o enfoque era diferenciado: eles pareciam ser levados mais a sério pelos acadêmicos, talvez por sua mais incisiva iconoclastia e também por atuarem numa época em que a Academia Brasileira de Letras já não apresentava o mesmo vigor e a mesma disposição de outrora para os embates literários. Por isso mesmo, relativamente aos modernistas, os acadêmicos pareciam sentir-se sensivelmente mais incomodados, um incômodo que se traduz, por exemplo, na clara indisposição do grupo diante de atitudes como as de Graça Aranha, celebrizado mais tarde pelo episódio da dissidência em favor da adoção generalizada de um espirito moderno (Bosi, 1977; Oliveira, 1993; Brito, 1974; Lopes, 1997).

Não eram poucos, portanto, os acadêmicos que se dispunham a combater em prol do ideário academicista e contra os novos literatos da oposição. Afrânio Peixoto, por exemplo - um acadêmico dos mais representativos, em função de sua assumida empatia para com a instituição -, não hesitou em terçar armas contra os "inimigos", assumindo não poucas vezes o papel de paladino das tradições literárias acadêmicas: temperamento pouco afeito a deblaterações calorosas e a polêmicas enérgicas, preferiu transpor para alguns romances a temática do litígio entre novos e antigos uma espécie de curiosa reabilitação literária, em tom menor, da célebre Querelle des ancients et des modernes, ocorrida durante a passagem para o século XVIII francês -, ainda que em poucos e circunstanciais episódios. Assim, em As Razões do Coração (1925), o romancista expõe dois personagens secundários dialogando a respeito das disputas travadas em torno de grupos literários distintos, os chamados "novos" (os modernistas) e "velhos" (os acadêmicos):

- Aqueles são 'novos'... - velhos que fossem, era o mesmo... um grupo clamoroso de 'novos'... agressivos porque supõem que lhes tomam o direito ao sol... Os velhos detêm editores e leitores... uma injustiça! (...). Ali quem não é imbecil é o Ricardo Sena, que se agita, para que não o esqueçam (...). E, com uma multidão, investe agora contra os consagrados, a Academia (...). Academia, à qual pertencerá, entretanto, como é de justiça... 
- (...) o divertido é que eles se dão ares de fazer coisa nova e original. Desde que o mundo é mundo foi sempre assim, velho contra novo, novo contra velho. Aristófanes versus Eurípedes, Focion versus Demóstenes... Antigos e modernos no século XVII, Perrault contra Boileau, clássicos e românticos no XIX, Lemercier contra Hugo... e não acaba..." (Peixoto, 1944, p. 13/14).

Tal diálogo pode ser tomado como um emblema das disputas a que aludimos há pouco, em que se revelam, inclusive, aspectos ligados ao contexto social da literatura ou à produção e recepção de textos literários, assinalando, por extensão, uma deliberada intenção de desautorizar o discurso dos novos literatos em favor do dos acadêmicos. É curioso, nesse sentido, perceber nas falas acima reproduzidas algumas marcas socioculturais a que já nos referimos, como a afirmação de que os acadêmicos detinham os editores e os leitores ou como a afirmação de que, cedo ou tarde, os novos literatos acabariam entrando para a Academia, como de fato ocorreria com alguns antigos desafetos dos acadêmicos. É mais do que um mero acaso, por exemplo, o fato de tanto simbolistas (como Félix Pachedo) quanto modernistas (como Manuel Bandeira) terem sido paulatinamente assimilados pela Academia Brasileira de Letras, embora numa época tardia, quando ela já estava descaracterizada como uma instituição cultural prevalente e esteticamente homogênea, amargando, inclusive, um período de franca decadência.

\section{O espírito antiacadêmico}

A estratégia da promoção ampla de um ideário encomiástico concretizada tanto em atitudes de natureza assumidamente bajulatória quanto em ataques irrestritos a qualquer indício de manifestação contrária ao academicismo - teve, evidentemente, o seu reverso, a sua contradita. Assim, pode-se afirmar que a Academia não foi apenas uma entidade cujos espaços institucionalizados eram avidamente almejados por todos aqueles que ambicionavam destacar-se no meio literário brasileiro, mas foi também - e com igual rigor - o alvo preferencial daqueles que dela não faziam parte, numa nítida reação à monopolização literária promovida pela ética e pela estética academicistas.

Assim, as reações contra a tentativa não-declarada de homogeneização estética a partir de um paradigma academicista não se fizeram esperar: da mesma maneira que podemos verificar um verdadeiro espírito gregário nos acadêmicos, formando o que há 
pouco chamamos de corporativismo, da parte dos antiacademicistas percebemos igualmente a tentativa de organizar, de modo informal, uma espécie de coro dos contrários, por meio do qual todos aqueles que de alguma maneira se sentissem marginalizados pela cultura institucionalizada ou apresentassem uma postura ética e/ou estética divergente da acadêmica pudessem criticar a instituição e seus membros pelo mesmo diapasão.

Algumas críticas, apesar da severidade dos ataques, eram esporádicas; outras, mais recorrentes. Antônio Torres, por exemplo, um crítico contumaz das personalidades e instituições culturais oficiais, destaca-se pela inclemência de seus ataques, não hesitando em chamar a Academia Brasileira de Letras, em crônica publicada em 1920, de "preguiçosa e inútil" (Torres, 1925, p. 62). Os ataques, ainda mais incisivos, ressurgem na correspondência trocada com Gastão Cruls, por volta da década de 1930, ao considerar a Academia Brasileira de Letras um autêntico "grêmio de patuscos" (Cruls, 1950, p. 343), e prognosticando sua breve transformação na "Academia Brasileira de Lixo" (Cruls, 1950, p. 240).

Outros, igualmente, não poupavam críticas à instituição, podendo-se encontrá-las em personalidades tão diferentes quanto Gilberto Amado, Frota Pessoa, Monteiro Lobato ou Graça Aranha. Um dos mais assíduos, contudo, era Lima Barreto, manifestandose, com sua célebre neurastenia e segundo uma ótica fundada no ressentimento, contra tudo aquilo que podia ser considerado iníquo e desarrazoado. Nesse sentido, podem-se destacar três vertentes críticas à Academia na produção literária de Lima Barreto: os ataques diretos à instituição, tendo evidentemente a Academia Brasileira de Letras como alvo principal; as críticas mediadas pela alegoria, em que a Academia e seus membros são ridicularizados de forma disfarçada; e as agressões indiretas, em que se critica o academicismo por meio de investidas à oficialidade literária.

Em relação à primeira vertente, avulta uma crônica, datada de 1921, em que Lima Barreto faz um comentário acintosamente pejorativo em relação à Academia e seus membros, nos seguintes termos:

em letras, temos a nossa Academia Brasileira - é verdade. É uma bela senhora, generosa, piedosa, religiosa; mas tem um defeito: só estima e julga com talento os seus filhos legítimos, naturais, espúrios e, mesmo, os adotivos. Quem não sugou o leite da academia ou não foi acalentado por ela, quando de colo, a rabugenta matrona não dá mérito algum. Daí, a falta de formalidade marcada nos felizes autores, 
velhos e novos, consagrados, cujos nomes não são acintosamente omitidos dos jornais (Barreto, 1956, p. 172).

Em relação à segunda vertente, lembramos que a alegoria foi um recurso bastante usado por Lima Barreto, como forma de criticar e atacar instituições e personalidades de sua época, as quais considerava injustas ou pouco éticas. Tal recurso pode ser facilmente exemplificado pela novela Os Bruzundangas (1923), em que a crítica à Academia Brasileira de Letras esconde-se sob os ataques desferidos aos literatos e aos acadêmicos da imaginária Bruzundanga. Também em "Harakashy e as Escolas de Java", uma curiosa estória de Lima Barreto, o romancista carioca destila seu fel irônico contra a Academia, ao tratar de algumas peculiaridades culturais de Batávia, ilha imaginária de Java, em que as semelhanças com o Brasil são mais do que mera coincidência; ao falar, especificamente, da Academia de Letras da ilusória região, afirma sarcasticamente:

a sua Academia de Letras é muito conhecida na rua principal da cidade, e os literatos da ilha brigam e guerreiam-se cruamente, para ocuparem um lugar nela. A pensão que recebem é módica (...); eles, porém, disputam o fauteuil acadêmico por todos os processos imagináveis. Um deles é o empenho, o nosso pistolão, que procuram obter de quaisquer mãos (...). Há de parecer que, por tão pouco, não valia a pena disputar acirradamente, como fazem, tais posições. É um engano. $\mathrm{O}$ sujeito, que é acadêmico, tem facilidade em arranjar bons empregos na diplomacia, na alta administração; e a grande burguesia da terra, burguesia de acumuladores de empregos, de políticos de honestidade suspeita, de leguleios afreguesados, de médicos milagrosos ou de ricos desavergonhados, cujas riquezas foram feitas à sombra de iníquas e aladroadas leis (...) tem em grande conta o título de membro da Academia, como todo outro qualquer, e o acadêmico pode bem arranjar um casamento rico ou coisa equivalente (Barreto, 1951, p. 28).

Em relação à terceira vertente, pode-se dizer que seus ataques àquilo que considerava uma espécie de estilo oficial, representado pela literatura academicista, perpassa quase todo seu espólio literário. A mesma crítica à padronização narrativa, que estaria presente tanto em seu primeiro romance (Recordações do Escrivão Isaías Caminha, 1909) quanto no último (Vida e Morte de M. J. Gonzaga de Sá, 1919), já se manifestara, como desencantada confissão, em 1905, no seu Diário Íntimo, ao atacar a subserviência dos literatos brasileiros aos escritores portugueses menores, numa clara crítica ao estilo de nossos acadêmicos: 
é uma literatura de clube, uma literatura imbecil, de palavrinhas, de coisinhas, não há neles um grande sopro humano, uma grandeza de análise, um vendaval de epopéia; o cicio lírico que há neles é mal encaminhado para a literatura estreitamente pessoal, no que de pessoal há de inferior e banal: amores ricos, mortes de parentes e coisas assim (Barreto, 1953, p. 68).

Semelhantes citações revelam, no conjunto, a dimensão da crítica limabarretiana contra a Academia e seus agregados, num posicionamento ideológico que guarda muito do mulato ressentido que, por duas vezes, inscreveu-se para uma vaga na Academia que tanto criticara, sem nunca ter obtido êxito, e que, além disso, viveu à margem da oficialidade literária de seu tempo, numa espécie de ostracismo perene (Barbosa, 1981; Borba, 1941). Mas guarda também - e aí reside, para nós, sua importância - uma das marcas mais prezadas da literatura do romancista carioca: seu realismo polêmico e sua inegável habilidade como retratista da sociedade de seu tempo.

Sua crítica à oficialidade literária, por exemplo, pontua bem a ascendência do academicismo de grande parte dos literatos do período, ao mesmo tempo em que o consagra como uma voz divergente dessa mesma oficialidade (Lins, 1976; Prado, 1976; Fantinati, 1978; Carvalho, 1972; Nadólskis, 1989). Por fim, como para Lima Barreto o pressuposto estético jamais deveria se desvincular de um pressuposto ético, também no âmbito ideológico suas idiossincrasias anti-academicistas se manifestavam com todo o vigor, revelando assim uma veemência crítica que ultrapassava em muito a mera desilusão de alguém social e literariamente renegado (Cury, 1981; Antônio, 1977; Resende, 1989), e fazendo dele um dos mais representativos anti-acadêmicos da República das Letras.

\section{Condições de formação do homo academicus}

Se os fenômenos socioliterários aqui referidos, com destaque para a ideologia encomiástica, são semelhanças circunstanciais entre os movimentos academicistas tratados, há ainda outras aproximações que se mostram mais relevantes para o entendimento do papel desempenhado pelo autor vinculado à Academia Brasileira de Letras e, sobretudo, para a compreensão da formação do que se poderia chamar de homo academicus.

Em seu capítulo sobre o academicismo literário na fase final do século XVIII luso-brasileiro, Antônio Cândido lembra que pelo 
menos três fenômenos socioliterários marcaram o surgimento e a manutenção daquilo que ele chamou de literatura congregada: o favorecimento de uma consciência de grupo entre os homens cultos da época, levando-os à produção literária de fato, identificando o indivíduo como letrado e definindo-lhe um status de escritor; a formação de um público leitor, tanto entre os próprios membros das Academias quanto entre os cidadãos em condições de consumir suas obras; a manutenção de uma cultura dominante e erudita, direta ou indiretamente ligada ao establishment político-administrativo e religioso (Cândido, 1981). De forma resumida, as palavras do mesmo crítico, em obra diversa, são bastante apropriadas:

a partir da metade do século XVIII já se pode falar pelo menos do esboço de uma literatura como fato cultural configurado, não apenas como produções individuais de pouca repercussão. A consciência de grupo por parte dos intelectuais, o reconhecimento que começou a existir de um passado literário local, o começo de maior receptividade por parte de públicos, embora débeis e pouco numerosos, começam a definir uma articulação dos fatos literários. Esta foi a importância decisiva do século XVIII, cuja base é o movimento das Academias de cujo coroamento será a plena consciência de autonomia no século XIX (Cândido, 1998, p. 27).

Essa é uma idéia recorrente no pensamento de Antônio Cândido, a que se pode acrescentar, ainda sobre a mesma época e ligada ao movimento academicista do período, a gênese do sentimento nativista brasileiro, que se traduzia em "atitudes nacionalistas em embrião" (Cândido, 1989, p. 167) ou no "desejo de mostrar que também nós tínhamos capacidade para criar uma expressão racional da natureza, generalizando o nosso particular mediante as disciplinas intelectuais aprendidas com a Europa" (Cândido, 1985, p. 97).

Mutatis mutandis, poderíamos considerar esses mesmos fenômenos como condicionantes da instauração dos academicismos oitocentista e novecentista: o agrupamento em torno da Academia Brasileira de Letras e, mais ainda, em torno do academicismo literário em sentido lato, trazia, a um só tempo, claras vantagens para os letrados do período, proporcionando-lhes um estatuto de escritor, concedendo-lhes as condições necessárias para seu sucesso junto ao público leitor, para sua atuação na imprensa, para a aceitação social, para a participação na cultura dominante local, para sua inserção em esferas administrativas do Estado, para a 
formação de uma consciência do intelectual e sua atuação na sociedade, base para a conformação de uma literatura nacional independente.

Esse sentido claro de valorização do acadêmico, de afirmação de sua identidade como homem de letras, enfim, de preservação de um status quo a muito custo adquirido, reverbera, ainda uma vez, os anseios do letrado do século XVIII, tal como se verificou na França de Luís XV, quando começa a se consolidar, de fato, um campo literário em que se assinala uma série de práticas sociais e culturais voltadas para a emancipação, para a consolidação e reconhecimento da gens de lettres (Goulemot, 1992; Viala, 1985; Roche, 1998).

Com as devidas ressalvas, esse mesmo espírito corporativista, ligado a interesses tanto pessoais quanto de mercado, imperou incontestavelmente durante a passagem do século XIX para o XX no Brasil, o que, sem dúvida alguma, trazia inúmeras vantagens ao literato brasileiro: além daquelas que citamos há pouco, uma pelo menos de incontestável importância: a recepção/veiculação de suas obras, lidas e consumidas senão pela totalidade do parco público leitor da época, ao menos por seus pares intelectuais. É o que mostra, por exemplo, a enquete promovida por João do Rio nas páginas da Gazeta de Notícias, a partir de 1905, e, posteriormente, publicada sob o sugestivo título O Momento Literário (1907) (Rio, 1994). Em suas reportagens para a Gazeta de Notícias, João do Rio entrevistou aqueles que considerava os principais escritores e intelectuais da época, arrolando uma série de perguntas, sobretudo a respeito de suas leituras preferenciais e influências literárias assumidas.

Analisando algumas das respostas dos intelectuais brasileiros para a pergunta que versava sobre a leitura preferida de cada um, obtemos informações bastante significativas. No que se refere especificamente à Literatura Brasileira, percebemos que os autores nacionais mais lidos eram contemporâneos à época da pesquisa (realistas, naturalistas, parnasianos), seguidos pelos românticos, pelos simbolistas e por outros (barrocos, árcades etc.). Entre todos os citados, destacam-se aqueles que, por algum motivo, estabeleciam uma relação estreita com certa oficialidade cultural, simbólica e praticamente representada, no período, pela Academia Brasileira de Letras, ainda que nem todos pudessem ser chamados de academicistas stricto sensu: Bilac, Machado de Assis, Coelho Neto, Alberto de Oliveira, Aluísio Azevedo, Raimundo Correa, 
Graça Aranha e outros. Mesmo entre as raras mulheres citadas, sobressaem aquelas que mantinham um vínculo informal com a estética academicista, representadas pelos nomes de Júlia Lopes de Almeida e Francisca Júlia.

Vejamos alguns desses dados ilustrados num gráfico, contendo a porcentagem de respostas relativas aos autores lidos, seguindo para tanto a seguinte tabela, limitada a alguns autores brasileiros:

A - Bilac;

B - Machado de Assis;

C - Alberto de Oliveira e Coelho Neto;

D - Aluísio Azevedo, Castro Alves, Fagundes Varela e Gonçalves Dias;

E - Graça Aranha e Raimundo Correa;

F - Curvelo de Mendonça, Cruz e Sousa, José de Alencar e Luís Delfino;

G - Euclides da Cunha;

H - Álvares Azevedo, Emílio de Meneses e Luís Murat;

I - Outros (66 autores).

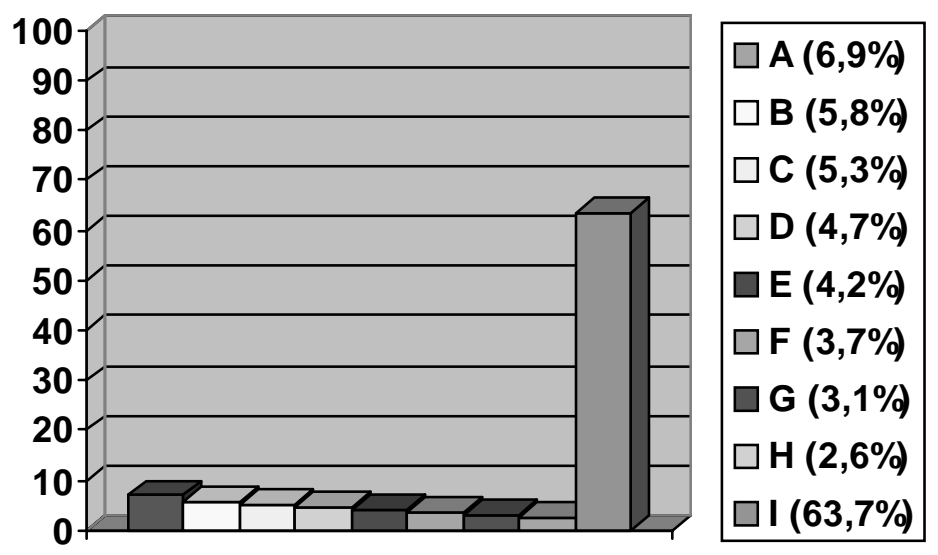

Como se pode facilmente comprovar, entre os autores citados como os mais lidos, encontram-se justamente aqueles que, direta ou indiretamente, mantinham um vínculo com a oficialidade literária representada pela Academia. A análise dos dados expostos vem confirmar - na medida em que inventaria, na sua maior parte, nomes comprometidos com o movimento academicista da passagem do século - outras idéias que, antes, tínhamos sugerido, principalmente a de que havia um espírito corporativista a conformar a boa parte da literatura produzida na época e a de que 
a filiação, formal ou informal, à estética e à ética academicistas redundava em inegáveis vantagens - do ponto de vista da recepção da obra literária - para os autores oficializados.

A hipótese de que esses mesmos autores - seguidos de outros que compactuavam com a estética academicista - também fossem lidos por um público menos intelectualizado, menos comprometido com o corporativismo acadêmico, revela-se plausível, se atentarmos para alguns indícios claros da recepção literária no período. Por exemplo, é significativa outra enquete, agora promovida pelo periódico A Semana, de Valentim Magalhães, em 1893, a respeito das obras e autores de Língua Portuguesa mais lidos pelo público, resultando na escolha de autores que, se não compactuavam integralmente com a estética academicista, ao menos possuíam um vínculo incondicional com a Academia Brasileira de Letras e todo seu entourage: principalmente Machado de Assis e Aluísio Azevedo. Outras enquetes populares - uma realizada por $O$ Malho e outra, pela Fon-Fon! - elegeram, respectivamente, Coelho Neto e Olavo Bilac, príncipes dos prosadores e dos poetas brasileiros. Fontes diversas nos dão conta ainda da acolhida pelo público leitor de nossos primeiros best-sellers, entre os quais encontram-se nomes de relevo no meio acadêmico, como Afrânio Peixoto (com A Esfinge, 1908). São dados incontestáveis - uma vez que pautados na suposta objetividade de enquetes e estatísticas -, que atestam a popularidade de autores ligados ao academicismo literário (Broca, 1960; Broca, 1993a; Broca, 1993b; Broca, 1991; Meneses, 1944; Meneses 1966; Meneses, 1953; Meneses, 1945; Meneses, 1958).

São esses pressupostos - mais sociais do que estéticos - que fundamentam a ideologia academicista, norteando o modo de atuação literário e social, e contribuindo de maneira decisiva para a formação do homo academicus.

\section{Referências}

ANTÔNIO, João. Calvário e Porres do Pingente Afonso Henriques de Lima Barreto. Rio de Janeiro: Civilização Brasileira, 1977.

BANDEIRA, Souza. Páginas Literárias. Rio de Janeiro: Francisco Alves, 1917. BARBOSA, Francisco de Assis. A Vida de Lima Barreto (1881-1922). Rio de Janeiro: José Olympio, 1981.

BARRETO, Lima. Histórias e Sonhos. Rio de Janeiro: Gráfica Editora Brasileira, 1951.

Diário Íntimo. Rio de Janeiro: Mérito, 1953.

Feiras e Mafuás. São Paulo: Brasiliense, 1956. 
BORBA, Osorio. O Inexplicável Ostracismo de Lima Barreto. A Comédia Literária. Rio de Janeiro: Alba, 1941, p. 111-115.

BOSI, Alfredo. As Letras na Primeira República. In: FAUSTO, Boris (dir.). História Geral da Civilização Brasileira. O Brasil Republicano. Sociedade e Instituições (1889-1930). Rio de Janeiro: Difel, 1977, tomo III, vol. 2, p. 293-319.

BRITO, Mário da Silva. História do Modernismo Brasileiro. Antecedentes da Semana de Arte Moderna. Rio de Janeiro: Civilização Brasileira, 1974.

BROCA, Brito. A Vida Literária no Brasil. 1900. Rio de Janeiro: José Olympio, 1960.

. Naturalistas, Parnasianos e Decadistas. Vida Literária do Realismo ao PréModernismo. Campinas: Unicamp, 1991.

. Teatro das Letras. Campinas: Unicamp, 1993a.

. Escrita e Vivência. Campinas: Unicamp, 1993b.

CÂNDIDO, Antônio. Formação da Literatura Brasileira (Momentos Decisivos). Belo Horizonte: Itatiaia, vol. 1, 1981.

. Literatura e Sociedade. Estudos sobre Teoria e História Literária. São Paulo: Nacional, 1985.

. A Educação pela Noite e Outros Ensaios. São Paulo: Ática, 1989. . Introdução à Literatura Brasileira (Resumo para Principiantes). São Paulo: Humanitas, 1998.

CARVALHO, Fernando. Lima Barreto. São Paulo: Faculdade de Filosofia, Ciências e Letras da USP, 1972 (Tese de Doutorado).

CASTELLO, José Aderaldo. O Movimento Academicista. In: COUTINHO, Afrânio (dir.). A Literatura No Brasil, Rio de Janeiro: Sul Americana, vol. I, 1968.

. Éditos e Inéditos do Movimento Academicista no Brasil. 1641-1820/ 22. O Movimento Academicista no Brasil. 1641-1820/22. São Paulo: Conselho Estadual de Cultura, vol. I, tomo I, 1969, p. VII-XXI.

. Manifestações Literárias do Período Colonial (1500-1808/1836). São Paulo: Cultrix/Edusp, 1975. 1999. . A Literatura Brasileira. Origens e Unidade (1500-1960). São Paulo: Edusp,

COELHO NETO. Livro de Prata. São Paulo: Livraria Liberdade, 1928.

COUTINHO, Afrânio. Introdução à Literatura no Brasil. Rio de Janeiro: Bertrand Brasil, 1988.

CRULS, Gastão. Antônio Torres e seus Amigos (Notas Bio-Bibliográficas seguidas de Correspondência). São Paulo: Companhia Editora Nacional, 1950.

CURY, Maria Zilda Ferreira. Um Mulato no Reino do Jambom (As Classes Sociais na Obra de Lima Barreto). São Paulo: Cortez, 1981.

FANTINATI, Carlos Erivany. O Profeta e o Escrivão. Estudo sobre Lima Barreto. São Paulo: ILPHA-Hucitec, 1978.

GOULEMOT, Jean M.; OSTER, Daniel. Gens de Lettres, Écrivains et Bohèmes. L'imaginaire Littéraire. 1630-1900. Paris: Minerve, 1992.

LIMA, Augusto de. Noites de Sabbado. Rio de Janeiro: Annuario do Brasil, 1923. 
LIMA, Yedda Dias. Academia Brasílica dos Acadêmicos Renascidos. Fontes e Textos. São Paulo: FFLCH/USP, 1980 (Tese de Doutorado).

LINS, Osman. Lima Barreto e o Espaço Romanesco. São Paulo: Ática, 1976.

LOPES, Marcos Aparecido. No Purgatório da Crítica. Coelho Neto e o seu Lugar na História da Literatura Brasileira. Campinas: Unicamp, 1997 (Dissertação de Mestrado).

MACHADO NETO, A. L. Estrutura Social da República das Letras (Sociologia da Vida Intelectual Brasileira. 1870-1930). São Paulo: Grijalbo/Edusp, 1973.

MENESES, Raimundo de. A Vida Boêmia de Paula Nei. São Paulo, Martins, 1944. . Emílio de Meneses. O Último Boêmio. São Paulo: Martins, 1945. . Guimarães Passos e sua Época Boêmia. São Paulo: Martins, 1953. . Aluísio Azevedo. Uma Vida de Romance. São Paulo: Martins, 1958. Bastos Tigre e "La Belle Époque". São Paulo: Edart, 1966.

MOISES, Massaud. História da Literatura Brasileira. Simbolismo. São Paulo: Cultrix/Edusp, 1984.

MURICI, Andrade. Panorama do Simbolismo Brasileiro. Rio de Janeiro, 1952.

NADÓLSKIS, Hêndricas. A Língua Literária de Lima Barreto: Traços Distintivos. São Paulo: FFLCH/USP, 1989 (Tese de Doutorado).

OLIVEIRA, Franklin. A Semana de Arte Moderna na Contramão da História e Outros Ensaios. Rio de Janeiro: Topbooks, 1993.

PEIXOTO, Afrânio. As Razões do Coração. Rio de Janeiro: W. M. Jackson, 1944. PRADO, Antonio Arnoni. Lima Barreto: O Crítico e a Crise. Rio de Janeiro/ Brasília: Cátedra/INL, 1976.

RESENDE, Beatriz. Dentes Negros Cabelos Azuis. Lima Barreto e a Cidadania em Fragmentos. Rio de Janeiro: UFRJ, 1989 (Tese de Doutorado).

RIO, João. O Momento Literário. Rio de Janeiro: Fundação Biblioteca Nacional/ Departamento Nacional do Livro, 1994.

ROCHE, Daniel. Les Républicains des Lettres. Gens de Culture et Lumières au XVIII ${ }^{e}$ Siècle. Paris: Fayard, 1988

TORRES, Antônio. Verdades Indiscretas. Rio de Janeiro: Livraria Castilho, 1925. VIALA, Alain. Naissance de l'Écrivain. Sociologie de la Littérature à l'Âge Classique. Paris: Minuit, 1985. 